\title{
Obesity and fragility fractures
}

\section{Obezite ve frajilite kırıkları}

\author{
Erkan MESCi
}

\begin{abstract}
Despite the dominant belief that obesity confers some protection against osteoporosis, several findings that contrast with this argument have been brought forward in recent years. While obesity is considered to be protective against fractures in some localizations such as hip, it is also regarded as a risk factor for fractures at other sites including humerus and wrist. Interactions between obesity and bone metabolism are multifaceted and complex. Since fracture-related complications are more common and functional improvement following recovery is poor in obese individuals, it is very important to establish the link between obesity and fracture and to predict subsequent fractures. In this article, the relationship between obesity and bone metabolism, the impact of obesity on risk factors related to the development of fractures, assessment of fracture risk in obese persons and the association of fracture site with obesity will be reviewed.
\end{abstract}

Key words: Bone metabolism, fracture, obesity, osteoporosis öz

Son yıllarda obezitenin osteoporoza karşı koruyucu olduğu yönündeki hâkim görüşe karşıt bulguların ön plana çıktığı görülmektedir. Obezite, kalça gibi bazı lokalizasyonlardaki kırıklar için koruyucu, humerus ve ayak bileği gibi lokalizasyonlar için ise risk faktörü olarak gösterilmektedir. Obezitenin kemik metabolizması ile ilişkisi çok yönlü ve karmaşıktır. Obez kişilerde kırık komplikasyonlarının daha sık görülmesi ve iyileşme sonrası elde edilen fonksiyonel düzelmenin yetersiz olabilmesi gibi nedenlerle; obezite kırık ilişkisinin aydınlatılması ve kırıkların öngörülebilmesi çok önemlidir. Bu derlemede, obezitenin kemik metabolizması ile ilişkisi, kırık oluşumu ile ilgili faktörler üzerine etkileri, obez kişilerde kırık riskinin değerlendirilmesi ve kırık lokalizasyonu ile obezite ilişkisi konuları gözden geçirilecektir.

Anahtar kelimeler: Kemik metabolizması, kırık, obezite, osteoporoz

\section{Giriş̧}

Obezite ve frajilite kırıkları dünya genelinde sıklıkları giderek artan iki önemli halk sağlığı sorunudur. Obezite diyabet, kardiyovasküler hastalıklar, inme gibi hastalıklarla bilinen ilişkileri dışında, son yıllarda frajilite kırığı riskini artırdığı yönünde giderek artan bulgular nedeniyle de dikkat çekmektedir ${ }^{1}$. Dünya Sağlık Örgütü (DSÖ) obeziteyi vücut kitle indeksinin 30 kg/ $\mathrm{m}^{2}$ ve üzerinde olması şeklinde tanımlamaktadır. Osteoporoz düşük kemik mineral yoğunluğu (KMY) ve kemik mikromimarisinin bozulması ile karakterize, kırık riskinin artmasına yol açan sistemik bir iskelet hastalığıdır². Düşük enerjili kırıklar postmenopozal dönemdeki kadınlarda önemli morbidite, mortalite ve yüksek ekonomik maliyet nedenidir. Kırıklara yol açan risk faktörlerinin belirlenmesi ve bunlarla mücadele stratejileri geliştirilmesi konusunda önemli mesafeler alınmıştır.

Dünya Sağlık Örgütü (DSÖ) tarafından aynı toplumdaki genç yetişkinlere göre KMY değerlerinin -2,5 standart sapmanın altında olması osteoporoz olarak tanımlanmıştır. Frajilite kırıklarının oluşması için KMY değerleri en önemli belirleyici olarak kabul edilmektedir. Yüksek VKi olan kişilerde yüksek KMY görülmesi ve kalça gibi bazı lokalizasyonlarda kırık sıklığının düşüklüğü yönündeki klinik gözlemlerin de etkisi ile uzun yıllar obezitenin kırıklara karşı koruyucu olduğu düşünülmüştür. Ancak son yıllarda obezitenin kırıklara karşı her zaman koruyucu olmadığı, yüksek VKi'nin yüksek KMY ile birlikte olmayabileceği, hatta osteopo-

Received: 23.01.2016

Accepted: 07.02.2016

İstanbul Medeniyet University Göztepe Education and Research Hospital Department of Physical Therapy and Rehabilitation

Yazışma adresi: Erkan Mesci, İstanbul Medeniyet University Göztepe Education and Research Hospital Department of Physical Therapy and Rehabilitation, İstanbul

e-mail: erkanmesci@hotmail.com 
roz ve obezitenin ortak patofizyolojik mekanizmaların sonucu olabileceği yönünde bulgulara ulaşılmıştır ${ }^{1,3,4}$. Obez kadınlarda vücut bölgelerinden bağımsız olarak genel kırık prevalansı obez olmayanlarla benzerdir ${ }^{5}$. Obezite kemik ilişkisi çok boyutlu ve karmaşık olup, birçok yönü ile henüz aydınlatılamamıştır ${ }^{6}$.

Geniş çaplı epidemiyolojik çalışmalar yüksek VKi'nin yüksek KMY değerleri ile ilişkili olduğunu ve bu durumun hem erkek hem de kadınlarda frajilite kırığı riskinde azalmaya neden olduğunu göstermiştir. Bu ilişkinin en kabul gören izahı yüksek vücut ağırlığının neden olduğu mekanik yüklenmenin kemik mineral yoğunluğunda artışa yol açmasıdır ${ }^{7}$. Gerçekten de yüksek VKi'nin artmış KMY ile ilişkisi pek çok çalışmada gösterilmiştir ${ }^{6,8,9}$. Yüksek yağ kitlesinin birkaç olumlu etkisi mevcuttur (Figür 1). Bunlardan birisi artmış mekanik yüklenmenin apopitozu azaltarak kemik formasyonunu uyarması ve osteoblast proliferasyonunu artırmasıdır ${ }^{6}$. Bunun dışında, geniş yağ doku kitlesi androjenlerin aromatizasyonu yolu ile östrojen sentezi sağlayarak KMY artışına neden olmaktadır ${ }^{10}$. Ancak ilerleyen yaşla birlikte bu etkinin önemini kaybettiği, bu nedenle postmenopozal kadınların obez olup olmamasına bakılmaksızın osteoporoz açısından takip edilmesi önerilmektedir ${ }^{11}$.

\section{Obezite kemik ilişkisinin fizyopatolojisi}

Obezite kemik ilişkisinin en önemli göstergelerinden birisi osteoblastlar ve adipositlerin aynı mezenkimal kök hücrelerden köken almalarıdır. Obezitenin neden olduğu artmış adipogenez, osteoblast yapımında azalmayı beraberinde getirmektedir ${ }^{6}$. Obezitenin kemik metabolizması üzerindeki olumsuz etkileri birkaç ana başlıkta toplanabilir (Figür 1). Obezitenin düşük seviyeli bir kronik enflamasyon ile ilişkili olduğu bildirilmektedir. Obez kişilerde dolaşımdaki IL- 6 ve TNF- $\alpha$ seviyelerinin yüksek olduğu saptanmıştır. Obezitenin proenflamatuvar sitokinler üzerinden nükleer faktör kappa B ligand reseptör aktivatörü (RANKL) upregülasyonuna ve sonuç olarak osteoklast aktivasyonuna neden olduğu düşünülmektedir6,12 (Figür 2). IL-6 ve TNF- $\alpha$ ayrıca insülin direncinin artmasına ve tip-2 diabet gelişimine neden olmaktadır. İnsülinin osteob- lastları stimüle ettiği, insülin direnci durumunda ise kemiğin olumsuz etkilendiği bilinmektedir ${ }^{13}$. Yüksek insülin düzeylerinin osteokalsin karboksilasyonunu azaltıp, RANKL yapımını artırarak kemik yıkımını artırdığı gösterilmiştir ${ }^{14}$.

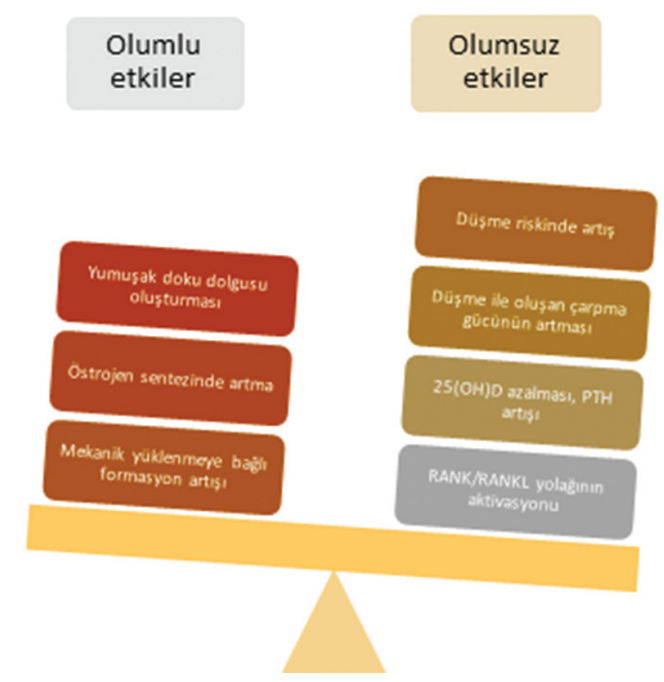

Figür 1. Obezitenin kemik üzerine olumlu ve olumsuz etkileri.

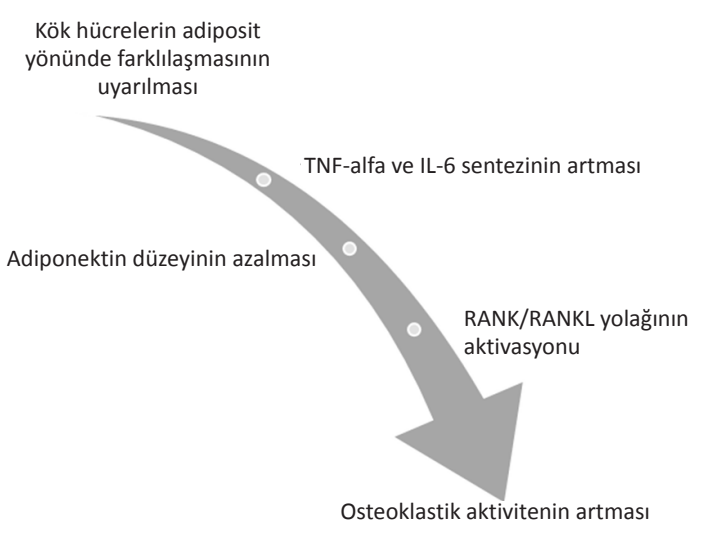

Figür 2. Obezitede osteoklastik aktiviteyi artıran faktörler.

Gerek obezite, gerekse osteoporozda yüksek genetik yatkınlık olduğu bilinmektedir. IL-6 reseptör gen polimorfizminin obezite ve osteoporoz eğilimi ile ilişkili olduğu gösterilmiştir ${ }^{15}$.

Adipokinler enflamasyon, endotel hasarı, atheroskleroz, insülin metabolizması, kemik döngüsü gibi pek çok fizyolojik ve patolojik süreçte etkili olan protein yapıda moleküllerdir ${ }^{12}$. Leptin yağ dokudan salınan ve miktarı vücuttaki yağ doku ile pozitif ilişki gösteren 
bir adipokindir. Osteoblast ve osteoklastlar üzerinden kemik metabolizmasını düzenleyici etkisi olduğu gösterilmiş olmakla birlikte, net etkisinin hangi yönde olduğu henüz anlaşılamamıştır ${ }^{12,16}$. Obezlerde sentezi artan IL-6, TNF- $\alpha$ gibi sitokinlerin etkisi ile kemik koruyucu bir adipokin olduğu düşünülen adiponektin yapımı azalmaktadır. Adiponektin ve reseptörleri osteoblastlarca sentezlenmektedir. In vitro ve in vivo çalışmalar kemik dokuda adiponektin artışının osteoklast yapımını inhibe, osteoblast yapımını ise stimüle ettiğini göstermiştir ${ }^{17}$.

Obezlerde kemik metabolizması bozuklukları ile enflamasyon ilişkisini düşündüren bir diğer bulgu da serum $C$ reaktif protein (CRP) düzeylerinin obezlerde yüksek olmasıdır ${ }^{6,12}$. Yüksek CRP düzeyleri aynı zamanda düşük KMY, kemik turnover göstergelerinin serum düzeylerinin artışı ve artmış kırık riski ile ilişkili bulunmuştur ${ }^{6}$.

Obezite serum 25-hidroksi vitamin D (25-OHD) düzeylerinin düşmesine neden olmaktadır. Serum parathormon (PTH) seviyeleri ise vücuttaki yağ kitlesi ile orantılı olarak artmaktadır. Yüksek PTH düzeyleri özellikle kortikal kemiği olumsuz etkileyerek; humerus ve ayak bileği gibi kortikal kemiğin yoğun bulunduğu bölgelerde kırık riskinin artmasına yol açmaktadır ${ }^{18}$. Obezlerde yağdan zengin diyetin intestinal kalsiyum emilimini de olumsuz etkilediği bildirilmektedir ${ }^{6}$.

Metabolik sendrom osteoporoz ilişkisi son yıllarda çok sayıda çalışmaya konu olmuştur. Von Muhlen ve ark. ${ }^{19}$ göre metabolik sendrom düşük KMY değerleri ile ilişkilidir. Bu çalışmada, metabolik sendrom artmış vertebra dışı kırık sıklığı ile ilişkili bulunmuştur. Farklı bir görüş olarak yaşlı kadınlarda abdominal yağ kitlesi yüksekliğinin kırık riskinde azalma ile ilişkili olduğu bildirilmiştir ${ }^{20}$. Serum lipid profilinin KMY ile ilişkisi karmaşıktır. Yüksek lipid düzeylerini artmış kırık riski ile ilişkilendiren yayınlar olduğu gibi, KMY artışına neden olduğunu bildiren yayınlar da mevcuttur ${ }^{21,22}$. Kim ve ark. ${ }^{23}$ göre yüksek HDL düzeyleri osteoporoza karşı koruyucu olup, KMY değerlerinde artış ve kırık riskinde azalma ile ilişkili bulunmuştur. Metabolik sendrom ve komponentleri ile olası KMY azalması ve artmış kı- rık riskinin ilişkisi tam olarak aydınlatılamamış olmakla birlikte, yağ dokudan salınan adipokinler, sitokinler gibi biyoaktif moleküllerin etkisi olabileceği düşünülmektedir ${ }^{12}$.

Obezite erkeklerde de artmış kırık riski ile ilişkilidir. Erkeklerde obezite ile ilişkili kırıkların pek çoğunun yüksek KMY'ye rağmen oluştuğu ve ciddi fonksiyonel kayıplarla sonuçlandığı bildirilmiştir ${ }^{24}$. Obez erkeklerde androjen eksikliği ile birlikte seyreden hipotalamohipofizer aks sorunları ve düşük serum $D$ vitamini düzeyleri olduğu gösterilmiştir ${ }^{25,26}$.

\section{Obezlerde kırık riski}

Yapılan bir çalışmada, 40 yaş üstü kırık geçiren kadın ve erkeklerden VKi düşük olanların mortalite riski daha yüksek bulunmuştur ${ }^{27}$. Ancak literatür genel olarak değerlendirildiğinde, kırık geçiren obez hastalarda nonunion, postoperatif komplikasyonlar, komorbidite, hastanede uzun yatış süreleri, yüksek VKi'nin rehabilitasyona olumsuz etkileri gibi nedenlerle obez olmayanlara göre morbidite ve ekonomik kayıpların daha yüksek olduğu görülmektedir ${ }^{1,5,28}$. Ayrıca obez kişilerde tedavi sonrasında uzun dönem yaşam kalitesinin daha düşük, fonksiyonel kayıpların ise daha fazla olduğu gösterilmiştir ${ }^{29}$. Bu nedenlerle obezlerde frajilite kırıklarının önlenebilmesi için kırık riskinin önceden belirlenebilmesi çok önemlidir.

Premaor ve ark. ${ }^{30}$ yüksek KMY değerlerine sahip olmalarına rağmen, obez kadınların, geçirilmiş eski kırık sıklığı açısından obez olmayan kadınlara benzer olduklarını göstermişlerdir. KMY kırık oluşumu için en önemli risk faktörü olmakla birlikte, tek etkili faktör değildir. KMY dışında yaş, eski kırıklar, ailede kırık öyküsü, glukokortikoid kullanımı, sigara, alkol gibi klinik faktörler de kırık riskini artırmaktadır ${ }^{1}$. Geçirilmiş el bileği kırıklarının KMY'den bağımsız olarak yeni el bileği kırık riskini üç kat, herhangi bir bölgede kırık riskini ise iki kat artırdığı bilinmektedir ${ }^{31}$.

Kırık risk faktörlerinden en önemlisi olarak kabul edilen KMY değerlerinin obezlerde genellikle yüksek oluşu kırık riski tahminini zorlaştırmaktadır. Bu durum 
$K M Y^{\prime}$ nin tek kriter olarak alınmadığı FRAX ${ }^{\circledR}$ gibi risk tahmin araçlarında bile kırık olasılığının beklenenden düşük hesaplanmasına neden olmaktadır ${ }^{5,30,32}$. FRAX yaş, eski kırık, steroid kullanımı, vücut kitle indeksi gibi klinik risk faktörleri ile birlikte KMY değerlerinin kullanıldığı hasta modellerini temel almaktadır ${ }^{33}$. FRAX ${ }^{\circledR \prime}$ ın özellikle KMY kullanılarak hesaplandığında, obezlerde kırık riskini değerlendirmede etkili bulunduğu gösterilmiştir ${ }^{30}$. Toplumumuz için yapılan bir çalışmada, özellikle FRAX ${ }^{\circledR}$ kalça skoru duyarlılık ve seçicilik açısından başarılı bulunmuştur ${ }^{34}$. FRAX ${ }^{\circledR}$ skorları kemik döngüsü belirteçleri ile de kuvvetli korelasyon göstermektedir ${ }^{35}$. Obezlerde kırık riskinin düşük olduğu algısı nedeni ile bu kişiler çoğunlukla yeterince tedavi edilmemektedir ${ }^{1}$. Obezlerde KMY değerlerinin sıklıkla normal veya osteopenik seviyelerde olması nedeni ile KMY'yi tek kriter almayan $F R A X^{\circledR}$ ve benzeri risk hesaplama yöntemlerinin kullanılması obez kişilerin osteoporoz ve kırıklardan korunması için çok önemlidir.

\section{Kırık lokalizasyonu ve obezite}

Ülkemizde osteoporotik kırık sıklığının giderek artmakta olduğu bilinmektedir ${ }^{36}$. Obezite kırık riski ilişkisi vücut bölgelerine bağlı olarak farklılıklar göstermektedir ${ }^{5,37}$. Gnudi ve ark. ${ }^{38}$ göre obezlerde humerus kırığı riski normal kilolulara göre üç kat daha fazladır. Literatür incelendiğinde yoğunlukla humerus kırı̆̆ı sıklığının obezlerde yüksek olduğu yönündeki bulgulara rastlanmaktadır ${ }^{37,39}$. Johnsson ve ark.'nın ${ }^{40}$ yaptığı metaanalizin sonuçları da yüksek VKi'nin humerus kırık riskini artırdığı yönündedir.

Obezlerde kalça ve pelvis kırıklarının daha az görüldüğü bildirilmektedir ${ }^{3,37}$. Kalça kırığı riskinin yüksek VKi’nin etkisi ile azaldığı bilinmekle birlikte, kalça kırıklı kadınların \%46'sının obez veya aşırı kilolu bulunması dikkat çekicidir ${ }^{41}$. Öte yandan Søgaard ve ark. ${ }^{42}$ göre abdominal obezite artmış kalça kırığı riskine neden olmaktadır. Gnudi ve ark..$^{38}$ obezlerde kalça kırığı riskini normal kilolulara göre daha düşük bildirmişlerdir. Yapılan metaanalizlerde de obezitenin kalça kırığı riskini azalttığı gösterilmiştir ${ }^{40,43,44}$.
Obezlerde vertebra kırıklarına daha sık rastlandığını bildiren araştırmalar mevcuttur ${ }^{45,46}$. Kim ve ark. ${ }^{23}$ göre vücut yağ oranı ve göbek çevresi KMY değerleri ile ters orantılı ve yüksek vertebra kırık riski ile ilişkilidir. Maghraoui ve ark. ${ }^{47}$ göre osteoporotik obez ve nonobez kadınlar arasında vertebra kırığı sıklığı açısından fark bulunmamaktadır. Premaor ve ark. ${ }^{48}$ göre ise obezlerde vertebra kırığı riski düşüktür. Aynı çalışmada, Obez erkeklerde çoklu kosta kırıklarının daha sık görüldüğü bildirmişlerdir.

Obezite ayak bileği kırıkları için de bir risk faktörü olarak gösterilmektedir ${ }^{5,47}$. Ancak ayak ve ayak bileği kırığı riskinin obeziteden etkilenmediği yönünde bulgular da mevcuttur ${ }^{38}$. Johansson ve ark.'nın ${ }^{40}$ yaptığı bir metaanalizin sonuçlarına göre, yüksek VKi alt ekstremite kırıkları için bir risk faktörüdür.

Obezitenin el bileği kırıklarını azalttığı yönünde bazı bulgular mevcuttur ${ }^{3,5}$. Yapılan bir metaanaliz ise yüksek VKi'nin ön kol kırıkları için riski artırdığını göstermiştir ${ }^{40}$. Bazı çalışmalarda kırık riskinin obeziteden etkilenmediği bildirilmiştir ${ }^{37}$. Literatür genel olarak değerlendirildiğinde, obezite, el bileği kırıkları ilişkisinin net olarak aydınlatılamadığı ortaya çıkmaktadır ${ }^{49}$.

Obezlerde kalça, omurga ve pelvis kırıklarının normal kilolulara göre daha erken yaşta oluştuğu gösterilmiştir. Bu durumun nedeni kesin olarak bilinmemekle birlikte, obezlerde düşme sıklığının yüksekliği, artmış parathormon düzeylerine bağlı olarak kortikal KMY değerlerinin düşük oluşu ve komorbidite gibi faktörlere dikkat çekilmektedir ${ }^{37,50}$. Obezlerde düşme sıkIığının daha fazla olduğu ve bunun artmış kırık riski ile ilişkisi bilinmektedir 5,38,51. Obez kişilerde düşmenin etkisi ile oluşan çarpma gücü; vücut ağırlığının fazlalığı nedeni ile normal kilolulara göre oldukça fazladır ${ }^{44}$. Gerçekten de çocuklarda pelvis kırıkları için yapılan similasyonlarda, obez çocukların kırıklara çok daha açık oldukları, obezite düzeyi arttıkça kırık oluşumu için gereken kritik çarpma hızının azaldığı saptanmış$\operatorname{tır}^{52}$. Obezitenin bazı bireylerde, olasılıkla yağ dokudan salınan proenflamatuvar sitokinlerin etkisi ile kas kitlesinin ve fonksiyonlarının azalmasına neden olduğu gösterilmiştir. Sarkopenik obezite olarak ad- 
landırılan bu durum artmış düşme sıklığı ve kırık riski ile ilişkili bulunmaktadır ${ }^{53}$.

Kırık oluşumunda pek çok faktörün etkili olması nedeni ile obezlerde KMY yüksekliğinin getirdiği avantaj kaybolmakta ve genel kırık sıklığının obezlerde daha düşük olmadığı görülmektedir ${ }^{5}$. Obezitenin kırık oluşumu ile ilgili üç temel etkisi mevcuttur. Bunlar kemiğin yük altında kalmasına bağlı olarak KMY'nin artışı, yağ dokunun yumuşak doku dolgusu oluşturması ve yüksek kilonun etkisi ile düşme sırasında oluşan çarpma gücünün artmasıdır ${ }^{44}$. Öyle görünmektedir ki bu üç faktörün karşılıklı etkileşimi, farklı vücut bölgelerinde kırık riskinin artmasına ya da azalmasına neden olmaktadır.

Genç erişkinlerdeki kırıklar incelendiğinde obezitenin kadınlarda kırık riski artışı ile ilişkili olduğu, erkekler içinse böyle bir etkinin gözlenmediği bildirilmiştir. Bu çalışmada, travmaların önlenmesi için aktif yaşam stilinin ve fiziksel aktivitenin önemi vurgulanmıştır ${ }^{54}$. Armstrong ve ark. ${ }^{55}$ göre fiziksel aktivite kalça kırığının azaltılması için bağımsız etkili bir faktördür. Gerçekten de fiziksel aktivite düzeyinin giderek azaldığı ileri yaştaki obez kadınlarda düşme korkusu ve postural stabilite bozukluklarında gözlenen artış, düşmeler için potansiyel risk olarak görülmektedir ${ }^{56}$.

Sonuç olarak, obezite kemik ilişkisine bakıldığında, kemik patolojilerinin sonuç etkisi olan kırıklar açısından, bu ilişkinin tek yönlü bir çıkarımla belirtilemeyeceği anlaşılmaktadır. Öyle görünmektedir ki obezitenin tüm kırıklara karşı koruyucu olduğu söylenemeyeceği gibi, obezitenin her kırık tipini artıran bir etken olduğu tezi de kabul görmeyecektir. Obezite kemik etkileşiminin iki yönlü ve karmaşık olduğu göz önüne alınarak, ana hedef olan kırıkların önlenmesi perspektifinden bakılmalı, gerek obez, gerekse obez olmayan hastalar KMY başta olmak üzere tüm kırık risk faktörleri açısından yeterli takip ve tedaviye tabi tutulmalıdır. Obezite kemik ilişkisi ayrıntılarının önümüzdeki yıllarda yeni araştırmalara konu olması ve yaşanacak olası gelişmelerin, obez olmayanlar dâhil olmak üzere osteoporoz fizyopatolojisine ve yeni tedavilere ışık tutması sürpriz olmayacaktır.

\section{KAYNAKLAR}

1. Premaor MO, Pilbrow L, Tonkin C, et al. Obesity and fractures in postmenopausal women. J Bone Miner Res 2010;25:292-7.

http://dx.doi.org/10.1359/jbmr.091004

2. NIH consensus development panel on osteoporosis prevention, diagnosis and therapy. Osteoporosis prevention, diagnosis and therapy. JAMA 2001;285:785-95.

3. Caffarelli C, Alessi C, Nuti R, Gonnelli S. Divergent effects of obesity on fragility fractures. Clin Interv Aging 2014;9:1629-36.

4. Pollock NK, Laing EM, Baile CA, et al. Is adiposity advantageous for bone strength? A peripheral quantitative computed tomography study in late adolescent females. Am J Clin Nutr 2007;86:1530-8.

5. Compston JE, Watts NB, Chapurlat R, et al. Obesity is not protective against fracture in postmenopausal women: GLOW. Am J Med 2011;124:1043-50.

http://dx.doi.org/10.1016/j.amjmed.2011.06.013

6. Cao JJ. Effects of obesity on bone metabolism. J Orthop Sur Res 2011;6:30.

http://dx.doi.org/10/1186/1749-799X-6-30

7. De Laet $C$, Kanis JA, Odén A, et al. Body mass index as a predictor of fracture risk: a meta-analysis. Osteoporos Int 2005;16:1330-8.

http://dx.doi.org/10.1007/s00198-005-1863-y

8. Compston J. Obesity and bone. Curr Osteoporos Rep 2013;11:30-5.

http://dx.doi.org/10.1007/s11914-012-0127-y

9. Holecki M, Zahorska-Markiewicz B, Chudek J, Wiecek A. Changes in bone mineral density and bone turnover markers in obese women after short-term weight loss therapy during a 5-year follow-up. Pol Arch Med Wewn 2010;120:248-54.

10. Migliaccio S, Greco EA, Fornari R, et al. Is obesity in women protective against osteoporosis? Diabetes Metab Syndr Obes 2011;4:273-82.

http://dx.doi.org/10.2147/DMSO.S11920

11. Silva HG, Mendonça LM, Conceição FL, et al. Influence of obesity on bone density in postmenopausal women. Arq Bras Endocrinol Metabol 2007;51:943-9.

http://dx.doi.org/10.1590/S0004-27302007000600008

12. Greco EA, Lenzi A, Migliaccio S. The obesity of bone. Ther Adv Endocrinol Metab 2015;6:273-86. http://dx.doi.org/10.1177/2042018815611004

13. Gonnelli S, Caffarelli C, Del Santo K, et al. The relationship of ghrelin and adiponectin with bone mineral density and bone turnover markers in elderly men. Calcif Tissue Int 2008;83:55-60. http://dx.doi.org/10.1007/s00223-008-9149-y

14. Clemens TL, Karsenty G. The osteoblast: an insülin target cell controlling glucose homeostasis. J Bone Miner Res 2011;26:677-80. http://dx.doi.org/10.1002/jbmr.321

15. Bustamante $M$, Nogués $X$, Mellibovsky L, et al. Polymorphisms in the interleukin- 6 receptor gene are associated with bone mineral density and body mass index in Spanish postmenopausal women. Eur J Endocrinol 2007;157:677-84. http://dx.doi.org/10.1530/EJE-07-0389

16. Barbour KE, Zmuda JM, Boudreau R, et al. Adipokines and the risk of fracture in older adults. J Bone Miner Res 2011;26:1568-76. http://dx.doi.org/10.1002/jbmr.361

17. Jurimae J, Rembel K, Jurimae T, Rehand M. Adiponectin is associated with bone mineral density in perimenopausal wo- 
men. Horm Metab Res 2005;37:297-302.

http://dx.doi.org/10.1055/s-2005-861483

18. Sukumar D, Schlussel Y, Riedt CS, et al. Obesity alters cortical and trabecular bone density and geometry in women. Osteoporos Int 2011;22:635-45. http://dx.doi.org/10.1007/s00198-010-1305-3

19. von Muhlen D, Safii S, Jassal SK, et al. Associations between the metabolic syndrome and bone health in older men and women: the Rancho Bernardo Study. Osteoporos Int 2007;18:1337-44.

http://dx.doi.org/10.1007/s00198-007-0385-1

20. Yang S, Nguyen ND, Center JR, et al. Association between abdominal obesity and fracture risk: a prospective study. J Clin Endocrinol Metab 2013;98:2478-83. http://dx.doi.org/10.1210/jc.2012-2958

21. Sivas F, Alemdaroğlu E, Elverici E, et al. Serum lipid profile: its relationship with osteoporotic vertebrae fractures and bone mineral density in Turkish postmenopausal women. Rheumatol Int 2009;29:885-90. http://dx.doi.org/10.1007/s00296-008-0784-4

22. Brownbill RA, Ilich JZ. Lipid profile and bone paradox: higher serum lipids are associated with higher bone mineral density in postmenopausal women. $J$ Womens Health (Larchmt) 2006;15:261-70.

http://dx.doi.org/10.1089/jwh.2006.15.261

23. Kim KC, Shin DH, Lee SY, et al. Relation between obesity and bone mineral density and vertebral fractures in Korean postmenopausal women. Yonsei Med J 2010;51:857-63. http://dx.doi.org/10.3349/ymj.2010.51.6.857

24. Nielson CM, Marshall LM, Adams AL, et al. BMI and fracture risk in older men: the osteoporotic fractures in men study (MrOS). J Bone Miner Res 2011;26:496-502. http://dx.doi.org/10.1002/jbmr.235

25. Orwoll E, Nielson CM, Marshal LM, et al. Vitamin D deficiency in older men. J Clin Endocrinol Metab 2009;94:1214-22. http://dx.doi.org/10.1210/jc.2008-1784

26. Bjontorp P, Rosmond R. Neuroendocrine abnormalities in visceral obesity. Int J Obes Relat Metab Disord 2000;24(Suppl 2):80-5. http://dx.doi.org/10.1038/sj.ijo.0801285

27. Prieto-Alhambra D, Premaor MO, Avilés FF, et al. Relationship between mortality and BMI after fracture: a populationbased study of men and women aged $\geq 40$ years. J Bone Miner Res 2014;29:1737-44. http://dx.doi.org/10.1002/jbmr.2209

28. Premaor MO, Comim FV, Compston JE. Obesity and fractures. Arq Bras Endocrinol Metabol 2014;58:470-7. http://dx.doi.org/10.1590/0004-2730000003274

29. Compston JE, Flahive J, Hooven FH, et al. Obesity, healt-care utilization, and Health-related quality of life after fracture in postmenopausal women: Global Longitudinal Study of Osteoporosis in Women (GLOW). Calcif Tissue Int 2014;94:223-31. http://dx.doi.org/10.1007/s00223-013-9801-z

30. Premaor $M$, Parker RA, Cummings $S$, et al. Predictive value of FRAX for fracture in obese older women. $J$ Bone Miner Res 2013;28:188-95. http://dx.doi.org/10.1002/jbmr.1729

31. Barrett-Connor E, Sajjan SG, Siris ES, et al. Wrist fracture as a predictor of future fractures in younger versus older postmenopausal women: results from the National Osteoporosis Risk Assessment (NORA). Osteoporosis Int 2008;19:607-13. http://dx.doi.org/10.1007/s00198-007-0508-8

32. Zhang $Z$, Shent $X$, Zhang $H$, et al. The relationship between body composition and fracture risk using the FRAX model in central south Chinese postmenopausal women. Clin Endocrinol (Oxf) 2012;77:524-30.

http://dx.doi.org/10.1111/j.1365-2265.2012.04399.x

33. http://www.sheffield.ac.uk/FRAX/tool.jsp?lang=tu

34. İpek A, Gafuroğlu Ü, Bodur H, Yılmaz Ö. Osteoporoz riskinin değerlendirilmesi. Türk Fiz Tıp Rehab Derg 2012;58:212-9. http://dx.doi.org/10.4274/tftr.42204

35. Uludağ $\mathrm{M}$, Akarırmak Ü, Özbayrak $\mathrm{S}$, ve ark. The Relationship Between the FRAX Tool and Bone Turnover Markers in Postmenopausal Osteoporosis. Turk J Osteoporos 2013;19:38-41.

36. Tuzun S, Eskiyurt N, Akarirmak U, et al. Incidence of hip fracture and prevalence of osteoporosis in Turkey: the FRACTURK study. Osteoporos Int 2012;23:949-55. http://dx.doi.org/10.1007/s00198-011-1655-5

37. Prieto-Alhambra D, Premaor MO, Avilés $F$, et al. The association between fracture and obesity is site-dependent: a population-based study in postmenopausal women. J Bone Miner Res 2012;27:294-300.

http://dx.doi.org/10.1002/jbmr.1466

38. Gnudi S, Sitta E, Lisi L. Relationship of body mass index with main limb fragility fractures in postmenopausal women. $J$ Bone Miner Metab 2009;27:479-84. http://dx.doi.org/10.1007/s00774-009-0056-8

39. Carnavale V, Morano S, Fontana A, et al. Assessment of fracture risk by the FRAX algorithm in men and women with and without type 2 diabetes mellitus: a cross-sectional study. Diabetes Metab Res Rev 2014;30:313-22. http://dx.doi.org/10.1002/dmrr.2497

40. Johansson $H$, Kanis JA, Odén $A$, et al. A meta-analysis of the association of fracture risk and body mass index in women. $J$ Bone Miner Res 2014;29:223-33. http://dx.doi.org/10.1002/jbmr.2017

41. Nielson CM, Srikanth P, Orwoll ES. Obesity and fracture in men and women: an epidemiologic perspective. J Bone Miner Res 2012;27:1-10. http://dx.doi.org/10.1002/jbmr.1486

42. Søgaard AJ, Holvik K, Omsland TK, et al. Abdominal obesity increases the risk of hip fracture. A population-based study of 43,000 women and men aged 60-79 years followed for 8 years. Cohort of Norway. J Intern Med 2015;277:306-17. http://dx.doi.org/10.1111/joim.12230

43. Tang X, Liu G, Kang J, et al. Obesity and risk of hip fracture in adults: a meta-analysis of prospective cohort studies. PLOS One 2013;8:e55077. http://dx.doi.org/10.1371/journal.pone.0055077

44. Ishii S, Cauley JA, Greendale GA, et al. Pleiotropic effects of obesity on fracture risk: the study of women's health across the nation. J Bone Miner Res 2014;29:2561-70. http://dx.doi.org/10.1002/jbmr.2303

45. Tanaka S, Kuroda T, Saito M, Shiraki M. Overweight/obesity and underweight are both risk factors for osteoporotic fractures at different sites in Japanese postmenopausal women. Osteoporos Int 2013;24: 69-76. http://dx.doi.org/10.1007/s00198-012-2209-1

46. Pirro M, Fabbriciani G, Leli $C$, et al. High weight or body mass index increase the risk of vertebral fractures in postmenopausal osteoporotic women. J Bone Miner Metab 2010; 28: 88-93. http://dx.doi.org/10.1007/s00774-009-0108-0

47. El Maghraoui A, Sadni S, El Maatoui A, et al. Influence of obesity on vertebral fracture prevalence and vitamin $D$ status in postmenopausal women. Nutr Metab (Lond) 2015;12:44. http://dx.doi.org/10.1186/s12986-015-0041-2

48. Premaor MO, Compston JE, Fina Avilés F, et al. The association between fracture site and obesity in men: a population- 
based cohort study. J Bone Miner Res 2013;28:1771-7. http://dx.doi.org/10.1002/jbmr.1878

49. Armstrong ME, Cairns BJ, Banks E, et al. Different effects of age, adiposity and physical activity on the risk of ankle, wrist and hip fractures in postmenopausal women. Bone 2012;50:1394-400.

http://dx.doi.org/10.1016/j.bone.2012.03.014

50. Gonnelli S, Caffarelli C, Nuti R. Obesity and fracture risk. Clin Cases Miner Bone Metab 2014;11:9-14. http://dx.doi.org/10.11138/ccmbm/2014.11.1.009

51. Beck TJ, Petit MA, Wu G, et al. Does obesity really make the femur stronger? BMD, geometry and, fracture incidence in the women's health initiative-observational study. J Bone Miner Res 2009;24: 1369-79.

http://dx.doi.org/10.1359/jbmr.090307

52. Kim JU, Hsieh MH, Soni BK, et al. Childhood obesity as a risk factor for bone fracture: a mechanistic study. Obesity (Silver Spring) 2013;21:1459-66.

http://dx.doi.org/10.1002/oby.20355
53. Stenholm S, Harris TB, Rantanen T, et al. Sarcopenic obesity: definition, cause and consequences. Curr Opin Clin Nutr Metab Care 2008;11:693-700.

http://dx.doi.org/10.1097/MCO.0b013e328312c37d

54. Jordan S, Lim L, Berecki-Gisolf J, et al. Body mass index, physical activity, and fracture among young adults: longitudinal results from the Thai cohort study. J Epidemiol 2013;23:435-42. http://dx.doi.org/10.2188/jea.JE20120215

55. Armstrong ME, Spencer EA, Cairns BJ, et al. Body mass index and physical activity in relation to the incidence of hip fracture in postmenopausal women. J Bone Miner Res 2011;26:1330-8. http://dx.doi.org/10.1002/jbmr.315

56. Dutil M, Handrigan GA, Corbeil $P$, et al. The impact of obesity on balance control in community-dwelling older women. Age (Dordr) 2013;35:883-90.

http://dx.doi.org/10.1007/s11357-012-9386-x 